\title{
Impaired Vasodilation of Forearm Resistance Vessels in Hypercholesterolemic Humans
}

\author{
Mark A. Creager, John P. Cooke, Michael E. Mendelsohn, Shelly J. Gallagher, \\ Sharon M. Coleman, Joseph Loscalzo, and Victor J. Dzau \\ Division of Vascular Medicine and Atherosclerosis, Brigham and Women's Hospital
}

and Harvard Medical School, Boston, Massachusetts 02115

\begin{abstract}
The effect of hypercholesterolemia on vascular function was studied in humans. To eliminate the potential confounding effects of atherosclerosis, vascular reactivity was measured in the forearm resistance vessels of 11 normal subjects (serum LDL cholesterol $=111 \pm 7 \mathrm{mg} / \mathrm{dl}$ ) and 13 patients with hypercholesterolemia (serum LDL cholesterol $=211 \pm 19 \mathrm{mg} / \mathrm{dl}, P$ $<0.05)$. Each subject received intrabrachial artery infusions of methacholine, which releases endothelium-derived relaxant factor, and nitroprusside which directly stimulates guanylate cyclase in vascular smooth muscle. Maximal vasodilatory potential was determined during reactive hyperemia. Vasoconstrictive responsiveness was examined during intra-arterial phenylephrine infusion. Forearm blood flow was determined by venous occlusion plethysmography. Basal forearm blood flow in normal and hypercholesterolemic subjects was comparable. Similarly, reactive hyperemic blood flow did not differ between the two groups. In contrast, the maximal forearm blood flow response to methacholine in hypercholesterolemic subjects was less than that observed in normal subjects. In addition, the forearm blood flow response to nitroprusside was less in hypercholesterolemic subjects. There was no difference in the forearm vasoconstrictive response to phenylephrine in the two groups. Thus, the vasodilator responses to methacholine and nitroprusside were blunted in patients with hypercholesterolemia. We conclude that in humans with hypercholesterolemia, there is a decreased effect of nitrovasodilators, including endothelium-derived relaxing factor, on the vascular smooth muscle of resistance vessels. (J. Clin. Invest. 1990. 86:228-234.) Key words: endothelium - endothelium-derived relaxing factor • limb circulation • vascular
\end{abstract}

\section{Introduction}

Studies in animals and humans with atherosclerosis have demonstrated abnormalities in vascular function. Depending upon the experimental model and the severity of atherosclerosis, one might observe impaired endothelium-dependent vasodilation, altered smooth muscle relaxation, or potentiated vasoconstriction to a variety of agonists (1-6). Vascular injury or dys-

Address reprint requests to Mark A. Creager, M.D., Division of Vascular Medicine and Atherosclerosis, Brigham and Women's Hospital, 75 Francis St., Boston, MA 02115.

Received for publication 14 June 1989 and in revised form 5 March 1990.

J. Clin. Invest.

(C) The American Society for Clinical Investigation, Inc. 0021-9738/90/07/0228/07 \$2.00

Volume 86, July 1990, 228-234 function secondary to hypercholesterolemia is likely a precipitating factor for atherosclerosis. Yet, the effect of hypercholesterolemia on vascular function in human vessels that are not atherosclerotic is not known. Several recent in vitro animal studies have suggested that hypercholesterolemia impairs endothelium-dependent vasorelaxation $(7,8)$. It has also been reported that increased levels of cholesterol potentiate vasoconstriction in canine coronary arteries (9). Thus, hypercholesterolemia may decrease synthesis, release, or transport of endothelium-derived relaxing factor(s), or alter the ability of the vascular smooth muscle to respond to vasoactive substances.

The purposes of this study were $(a)$ to test the hypothesis that vascular reactivity is altered in vivo in humans with hypercholesterolemia and $(b)$ to examine the potential site of functional impairment (endothelium or smooth muscle) in the vessel wall. To eliminate the potential confounding effects of atherosclerosis, we examined vascular reactivity in forearm resistance vessels (10). It was reasoned that the incidence of atherosclerosis is low in the upper extremity. Furthermore, unlike the walls of the larger arteries, the walls of resistance vessels do not develop atheroma after exposure to high levels of cholesterol (11). The results indicate that hypercholesterolemia, in the absence of atherosclerosis, is associated with impaired smooth muscle vasorelaxation.

\section{Methods}

Subjects. The control subject population in this study included 11 normal volunteers comprised of nine males and two females whose ages ranged from 22 to 43 and averaged $31 \pm 2$ yr. Normalcy was determined by a careful history and physical examination and laboratory analyses to exclude those with hematologic, renal, or hepatic dysfunction. There were 13 patients with hypercholesterolemia. Hypercholesterolemia was defined as a serum LDL cholesterol level greater than the 75 th percentile adjusted for age and sex. These individuals included 12 males and 1 female whose ages ranged from 24 to 45 and averaged $35 \pm 2 \mathrm{yr}$. The ages of the normal volunteers and patients with hypercholesterolemia were not significantly different. None of the patients had historical or physical evidence of atherosclerosis as determined by the absence of symptoms of angina, claudication, cerebrovascular ischemia, and no clinical evidence of arterial occlusive disease as would be suggested by decreased pulses, asymmetric blood pressure, or bruits. In addition, no patient had hypertension, diabetes mellitus, or congestive heart failure. None of the subjects were taking diuretics, vasoactive medications, or nonsteroidal anti-inflammatory medications. This study was approved by the Human Research Committee of Brigham and Women's Hospital and each subject gave written informed consent.

Experimental protocol. Each subject was studied in a $22^{\circ} \mathrm{C}$ temperature-controled room in the postabsorptive state. Alcohol, caffeine, and cigarettes were all prohibited within $12 \mathrm{~h}$ of the study. Under local anesthesia and sterile conditions, a polyethylene catheter was inserted into a brachial artery of each subject for determination of blood pres- 
sure and for infusion of drugs. The vascular research laboratory was quiet and lights were dimmed. All subjects rested at least $30 \mathrm{~min}$ after catheter placement to establish a stable baseline before data collection.

During the control period, measurements of forearm blood flow and blood pressure were repeated every $10 \mathrm{~min}$ until stable. Dextrose (5\%) was infused intra-arterially at a rate of $0.4 \mathrm{ml} / \mathrm{min}$ during the control period. To determine the maximal vasodilator potential of the resistance vessels, forearm blood flow was measured in the basal state and during reactive hyperemia after $5 \mathrm{~min}$ of an ischemic stimulus. Ischemia was induced by inflation of a sphygmomanometric cuff on the upper arm to suprasystolic pressure. Abnormalities in reactive hyperemic blood flow often imply structural problems in the resistance vessels preventing maximal vasodilation. Forearm blood flow measurements were repeated when basal conditions were reestablished.

To assess specifically endothelium-dependent vasodilation, methacholine chloride (a congener of acetycholine) was administered via the brachial artery. Forearm blood flow was measured during infusion of increasing concentrations of methacholine at doses of $0.03,0.3,3$, and $10 \mathrm{mcg} / \mathrm{min}$, each for $5 \mathrm{~min}$, delivered at a rate of $0.4 \mathrm{ml} / \mathrm{min}$. To distinguish abnormalities in endothelial function from abnormalities of vascular smooth muscle, subjects received an intra-arterial infusion of sodium nitroprusside. This agent, which acts directly on vascular smooth muscle by stimulating soluble guanylate cyclase and inducing hyperpolarization, was given at doses of $0.03,0.3,3$, and $10 \mu \mathrm{g} / \mathrm{min}$, at a rate of $0.4 \mathrm{ml} / \mathrm{min}$, each for 5 -min periods. To evaluate the vasoconstrictor responsiveness of the forearm resistance vessels, each subject then received intra-arterial phenylephrine, an alpha-1 adrenergic agonist, at incremental dosages of $0.3,1$, and $3 \mu \mathrm{g} / \mathrm{min}$, at a rate of 0.4 $\mathrm{ml} / \mathrm{min}$. Basal conditions were reestablished before each intervention. The doses of each drug were chosen to achieve decreases in forearm vascular resistance without causing systemic effects. Dose-response curves were generated for each drug infusion.

Evaluation of methacholine's mechanism of action. In this experiment, methacholine is used to evoke release of endothelium-derived relaxing factor. It is possible that vasodilation caused by methacholine is mediated by release of prostacyclin or affected by release of a cyclooxygenase-dependent endothelium-derived contracting factor (12). Alternatively, methacholine may have inhibited the release of norepinephrine at the neuro-effector junction, thereby causing vasodilation (13). To examine these possibilities, the effects of both aspirin and phentolamine were studied in five subjects, aged $38 \pm 3 \mathrm{yr}$. To evaluate the effect of cyclooxygenase inhibition, the forearm vascular response to methacholine was studied before and after aspirin treatment, 325 mg orally, three times daily for $3 \mathrm{~d}$. To exclude the possibility that methacholine interfered with adrenergic neurotransmission, the response to methacholine was also studied before and during intra-arterial infusion of phentolamine at a dose of $50 \mu \mathrm{g} / \mathrm{min}$. This dose of phentolamine was chosen because it had been demonstrated in previous studies to inhibit the vasoconstrictive response to an intra-arterial bolus of norepinephrine $(2 \mathrm{mcg})$ from 68 to 6 percent $(P<0.005)(14)$.

Hemodynamic measurements. Bilateral forearm blood flow was determined by venous occlusion strain gauge plethysmography, using calibrated mercury-in-silastic strain gauges, and expressed as milliliter per $100 \mathrm{ml}$ of tissue per minute (D. E. Hokanson, Inc., Issaquah, WA) (10). Each arm was supported above heart level. Venous occlusion pressure averaged $35 \pm 1 \mathrm{mmHg}$. Circulation to the hand was stopped by inflating a wrist cuff to suprasystolic pressures before each forearm blood flow determination. Each forearm blood flow determination comprised at least five separate measurements performed at 10-15-s intervals. By measuring blood flow in the infused arm, one can determine the direct effect of the vasoactive drug. By measuring blood flow in the noninfused arm, one could be assured that systemic effects have not occurred if no change in blood flow developed during the drug infusion. Forearm vascular resistance was calculated as the ratio of mean blood pressure to forearm blood flow and expressed as units reflecting $\mathrm{mmHg}$ per $\mathrm{ml} / 100 \mathrm{ml}$ of tissue per minute.

Blood pressure was measured via an arterial cannula that was at- tached to a Statham P23 pressure transducer aligned to an amplifier on a Gould physiologic recorder. Heart rate was determined from a simultaneously obtained electrocardiographic signal and calculated from the $\mathbf{R} \mathbf{R}$ interval.

Statistical analysis. Forearm blood flow, blood pressure, and heart rate data are presented as mean \pm SE. Statistical analysis used analysis of variance of independent groups for repeated measures for parametric data, followed by Newman-Keuls post-hoc testing for statistical significance (15). The Wilcoxon rank sum test was used for nonparametric data (16). For nonserial measurements, the $t$ test was used to analyze the difference between the means in each group. Linear regression analysis was performed for selected hemodynamic variables. Statistical significance was accepted at the $95 \%$ confidence level $(P$ $\leq$ 0.05).

\section{Results}

Lipid profile. The lipid profile in the study subjects is provided in Table I. As defined by enrollment criteria, the plasma total cholesterol and LDL cholesterol were significantly higher in the hypercholesterolemic patients than in the normal subjects. There was no significant difference in the plasma HDL cholesterol, VLDL cholesterol, or triglyceride levels between the two groups of subjects.

Basal and reactive hyperemic forearm blood flow. Basal blood flow in normal subjects and hypercholesterolemic subjects was comparable and averaged $2.9 \pm 0.3$ and $3.1 \pm 0.6$ $\mathrm{ml} / 100 \mathrm{ml}$ of tissue per minute, respectively $(P=\mathrm{NS})$ (Fig. 1). Similarly, reactive hyperemic blood flow in normal subjects was not different from that in hypercholesterolemic subjects and averaged $23.7 \pm 1.6$ and $26.6 \pm 2.0 \mathrm{ml} / 100 \mathrm{ml}$ of tissue per minute, respectively $(P=$ NS) (Fig. 1). Furthermore, forearm vascular resistance at baseline $(31.0 \pm 3.0$ vs. $39.5 \pm 5.3 \mathrm{U}$, respectively) and during reactive hyperemia ( $3.6 \pm 0.3$ vs. $3.5 \pm 0.3$ $\mathrm{ml} / 100 \mathrm{U}$, respectively) did not differ between the two groups of subjects.

Response to methacholine chloride. Mean blood pressure at baseline was $80 \pm 2 \mathrm{mmHg}$ in normal subjects and $87 \pm 2$ $\mathrm{mmHg}$ in hypercholesterolemic subjects $(P=\mathrm{NS})$. Basal heart rate was $58 \pm 2$ and $66 \pm 4$ in normal and hypercholesterolemic subjects respectively $(P=\mathrm{NS})$. The'incremental intra-arterial infusion of methacholine caused no changes in systemic blood pressure or heart rate in either group of subjects.

The forearm blood flow response to methacholine in normal and hypercholesterolemic subjects is illustrated in Fig. 2. The maximal forearm blood flow response to methacholine in normal subjects was $20.1 \pm 2.8$ and in hypercholesterolemic subjects was $14.2 \pm 2.6 \mathrm{ml} / 100 \mathrm{ml}$ of tissue per minute $(P$

Table I. Lipid Profile in Normal and Hypercholesterolemic Subjects

\begin{tabular}{lcc}
\hline & Normal & Hypercholesterolemic \\
\hline & \multicolumn{2}{c}{$m g / d l$} \\
Total cholesterol & $178 \pm 7$ & $275 \pm 19^{*}$ \\
LDL cholesterol & $111 \pm 7$ & $211 \pm 19^{*}$ \\
HDL cholesterol & $46 \pm 3$ & $44 \pm 3$ \\
VLDL cholesterol & $19 \pm 2$ & $19 \pm 2$ \\
Triglyceride & $116 \pm 10$ & $122 \pm 9$
\end{tabular}

Mean \pm SE. ${ }^{*} P<0.05$ vs. normal subjects. 


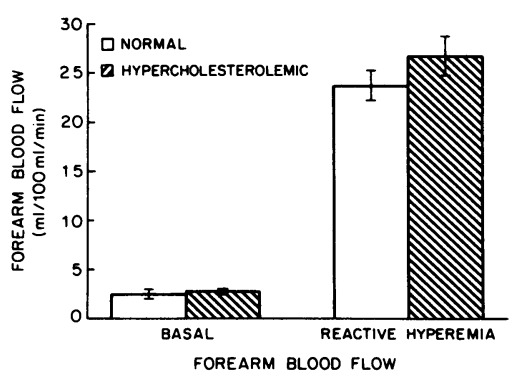

Figure 1. Forearm blood flow under basal conditions and during reactive hyperemia in normal and hypercholesterolemic subjects. Mean \pm SEM.

$<0.05)$. Compared to normal subjects, the vasodilator response to methacholine was blunted in patients with hypercholesterolemia. This achieved statistical significance at the 3and $10-\mu \mathrm{g} / \mathrm{min}$ doses. No changes in forearm blood flow occurred in the noninfused arm in either subject group.

Since there was no change in blood pressure, the change in forearm blood flow during the methacholine infusion reflected changes in forearm vascular resistance. The forearm vascular resistance was significantly less in the normal subjects than in the hypercholesterolemic subjects during the methacholine infusions of $3 \mu \mathrm{g} / \mathrm{min}(5.8 \pm 0.5$ vs. $11.0 \pm 2.5 \mathrm{U}, P<0.05)$ and 10 $\mu \mathrm{g} / \mathrm{min}(4.5 \pm 0.5$ vs. $10.6 \pm 2.9 \mathrm{U}, P<0.05)$. These data demonstrate that endothelium-dependent vasodilation is impaired in patients with hypercholesterolemia, but do not exclude a functional abnormality in vascular smooth muscle.

Response to nitroprusside. To determine whether hypercholesterolemia affects smooth muscle function directly, the vasodilator response to sodium nitroprusside was examined. Intra-arterial infusion of sodium nitroprusside did not change mean blood pressure or heart rate in either group. Compared to normal subjects, the forearm blood flow response to sodium nitroprusside was blunted in patients with hypercholesterolemia (Fig. 3). At a dose of $10 \mu \mathrm{g} / \mathrm{min}$, forearm blood flow was significantly greater in normal subjects than in hypercholesterolemic subjects $(16.0 \pm 1.9 \mathrm{vs} .11 .6 \pm 1.9 \mathrm{ml} / 100 \mathrm{ml}$ of tissue per minute $P<0.05$ ). No changes in forearm blood flow occurred in the noninfused arm of either group. The forearm vascular resistance was significantly less in normal than hypercholesterolemic subjects during the nitroprusside infusions of $3 \mu \mathrm{g} / \mathrm{min}(8.3 \pm 0.8$ vs. $13.5 \pm 1.9 \mathrm{U}, P<0.05)$ and $10 \mu \mathrm{g} / \mathrm{min}$ (5.7 \pm 0.7 vs. $9.4 \pm 1.2 \mathrm{U}, P<0.05)$. Decreased responsiveness to both methacholine and nitroprusside suggest that hypercholesterolemia impairs the effect of endogenous and exogenous nitrovasodilators on smooth muscle relaxation.

Response to phenylephrine. Potentiated vasoconstriction to endogenous substances may limit vasodilation. To evaluate

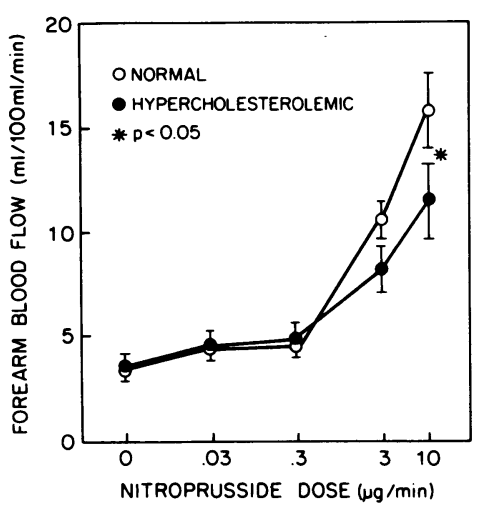

Figure 3. Forearm blood flow response to sodium nitroprusside in normal and hypercholesterolemic subjects. Mean \pm SEM.

vasoconstrictor responsiveness, intra-arterial phenylephrine was administered to both groups of subjects. The phenylephrine infusion did not change blood pressure or heart rate. The lowest forearm blood flow achieved with this intervention was $1.8 \pm 0.2 \mathrm{ml} / 100 \mathrm{ml}$ of tissue per minute in the normal subjects and $2.1 \pm 0.3 \mathrm{ml} / 100 \mathrm{ml}$ of tissue per minute in the hypercholesterolemic subjects $(P=\mathrm{NS})$. At no point in the dose response curve was there any significant difference in forearm blood flow between the two groups of subjects (Fig. 4). Similarly, the effect of phenylephrine on forearm vascular resistance was comparable in each group. Forearm blood flow and forearm vascular resistance did not change from basal values in the noninfused arm in either group of subjects.

Relationship of vasodilation with methacholine to nitroprusside. A blunted forearm vasodilator response to the methacholine infusion did not occur uniformly in all hypercholesterolemic subjects. In fact, some hypercholesterolemic subjects displayed increases in forearm blood flow during this intervention that overlapped with those observed in normal subjects. Similarly, the maximal forearm blood flow response to nitroprusside in some hypercholesterolemic subjects fell within normal confidence limits.

To determine whether the impaired vasodilator responses to methacholine and nitroprusside occurred in the same subjects, a linear regression analysis was performed correlating the percent of reactive hyperemic blood flow achieved with each drug in each subject. There was a strong direct correlation between the vasodilator response to methacholine and nitroprusside $(r=0.87, P<0.001)$. This correlation indicates that the blunted vasodilation to both drugs occurred in the same individuals and suggests a common mechanism underlying abnormal vasorelaxation in these subjects.

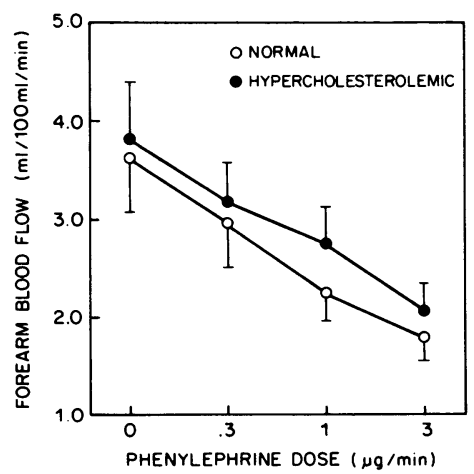

Figure 4. Forearm blood flow response to phenylephrine in normal and hypercholesterolemic subjects. Mean \pm SEM.

flow response to blood line chloride in normal and hypercholesterolemic subjects. Mean \pm SEM.

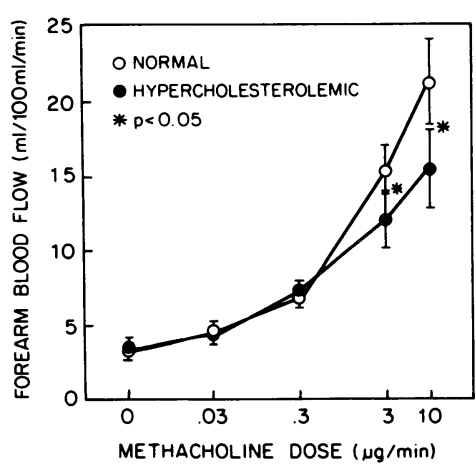

Creager, Cooke, Mendelsohn, Gallagher, Coleman, Loscalzo, and Dzau 
Evaluation of methacholine's mechanism of action. To exclude the possibility that vasodilation caused by methacholine was influenced by products of cyclo-oxygenase, the forearm vascular response to methacholine was studied in five normal subjects before and after aspirin therapy. Basal forearm vascular resistance was $41 \pm 6$ and $42 \pm 11 \mathrm{U}$ before and after aspirin treatment, respectively $(P=N S)$. Aspirin did not influence the forearm vasodilator response to intra-arterial methacholine (Fig. 5).

To determine whether methacholine mediated vasodilation by inhibiting prejunctional release of norepinephrine, these five subjects received intra-arterial phentolamine. As expected, phentolamine increased basal forearm blood flow (from $2.4 \pm 0.5$ to $6.4 \pm 1.0 \mathrm{ml} / 100 \mathrm{ml}$ of tissue per minute, $P$ $<0.05$ ) and decreased basal forearm vascular resistance (from $42 \pm 11$ to $15 \pm 3 \mathrm{U}, P<0.01$ ). Nonetheless, phentolamine did not affect the maximal forearm blood flow response to methacholine $(17.0 \pm 2.7$ vs. $19.8 \pm 2.7 \mathrm{ml} / 100 \mathrm{ml}$ of tissue per minute, $P=\mathrm{NS}$ ), nor blunt the maximal decrement in forearm vascular resistance ( $5 \pm 1$ vs. $5 \pm 1 \mathrm{U}, P=\mathrm{NS})$.

\section{Discussion}

Hypercholesterolemia accelerates atherosclerosis, a process which is generally considered to affect large and medium sized conduit arteries. Abnormalities in the function of these vessels have been reported in animals and humans with atherosclerosis $(1,3-6,17)$. Several recent studies have reported that relaxation of rabbit and porcine vascular rings exposed to hypercholesterolemic conditions is abnormal $(7,8)$. The fact that these rings were not atherosclerotic suggests that vascular dysfunction secondary to hypercholesterolemia may precede the development of atherosclerosis. Whether such an abnormality is also seen in resistance vessels is not known. The study reported herein was designed to determine if hypercholesterolemia affects vascular reactivity of resistance vessels, in vivo, in humans. The important new finding resulting from these experiments is that hypercholesterolemia impairs vasodilation in resistance vessels that are not atherosclerotic.

Impaired vasodilation in hypercholesterolemia may be the outcome of any one of several mechanisms, including functional abnormalities of the endothelium or vascular smooth muscle, or structural changes in the blood vessel that limit vasodilation. The following discussion will explore which of these possible mechanisms may explain the results of this study.

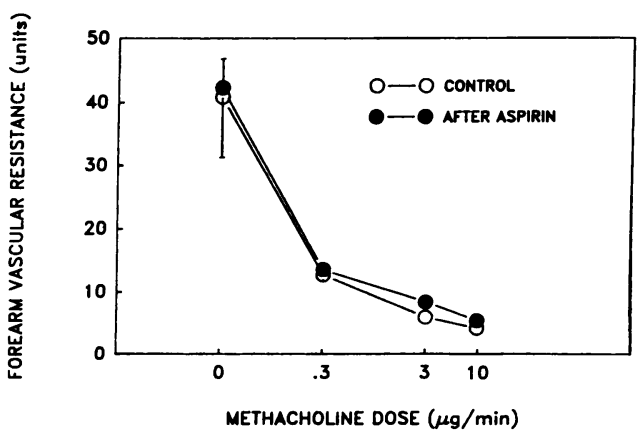

Figure 5. The effect of aspirin on the forearm vascular response to methacholine. Mean \pm SEM.
Functional abnormalities of the endothelium. The endothelium plays a major role in modulating vascular smooth muscle tone by synthesizing and metabolizing many vasoactive substances. Endothelial dysfunction may impair vasodilation by affecting release of vasodilator agents such as endothelium-derived relaxing factor (EDRF), ${ }^{1}$ a recently described vasodilator. EDRF has been found in a wide range of species including man (18-20). It is most likely a nitrovasodilator since its action is associated with an increase in cyclic GMP levels and is antagonized by agents that inhibit soluble guanylate cyclase $(21,22)$. Accumulating evidence suggests that EDRF is related to or identical to nitric oxide, derived from arginine (23).

The action of EDRF is impaired in atherosclerotic conduit vessels from rabbits, monkeys, and swine fed high cholesterol diets (4-6). Importantly, endothelium-dependent relaxations are attenuated in atherosclerotic human arteries $(17,24,25)$. The observation that endothelium-dependent vasodilation of conduit vessels is abnormal in the presence of atherosclerosis is not surprising. The thickened intima associated with atherosclerosis may act as a physical or functional barrier to prostacyclin and EDRF released from the endothelium. Furthermore, there is a loss of endothelial cells from the vessel wall as atherosclerosis progresses (26). However, morphologic changes in the endothelium cannot be the sole explanation, since endothelium-dependent vasorelaxation also is abnormal in the microcirculation of rabbits with diet-induced atherosclerosis $(27,28)$.

Recent evidence suggests that endothelial dysfunction may occur very early in hypercholesterolemic states, in the absence of atherosclerosis. Cohen et al. (8) observed endothelial dysfunction in coronary arteries isolated from swine fed a high cholesterol diet for 9 wk. Endothelium-dependent relaxations to serotonin and substance $P$ were diminished in the absence of any gross or microscopic evidence of atherosclerosis. Andrews et al. (7) examined the in vitro effects of low density lipoprotein upon endothelium-dependent vasorelaxation. Vascular relaxation to acetylcholine chloride was attenuated by incubation with low density lipoprotein. These two studies suggest that reduced endothelium-dependent vasodilation of conduit arteries may occur in hypercholesterolemic states and precede the development of atherosclerosis.

To determine if endothelium-dependent vasodilation of resistance vessels was impaired by hypercholesterolemia in man, we measured the forearm blood flow response to intra-arterial infusions of the muscarinic agonist, methacholine chloride. Stimulation of muscarinic receptors on the endothelium releases EDRF in a wide variety of vascular beds in all mammalian species studied, and in particular, induces endotheliumdependent relaxation in human limb arteries in vitro (18-20). It is unlikely that methacholine chloride caused vasodilation by releasing prostacylin or by causing prejunctional inhibition of adrenergic neurotransmission, since the forearm vascular effects of methacholine chloride were unaffected by either aspirin or phentolamine.

Vasodilation in response to methacholine chloride was blunted in the hypercholesterolemic subjects. This finding might be explained by reduced release or transport of EDRF from the endothelium. However, in this study, the impaired responsiveness to methacholine chloride cannot be explained

1. Abbreviation used in this paper: EDRF, endothelium-derived relaxing factor. 
entirely by endothelial dysfunction, since the response to sodium nitroprusside was also reduced in the hypercholesterolemic subjects.

Abnormalities of vascular smooth muscle. Nitroprusside causes vasodilation that is largely independent of the endothelium. Removal of the endothelium does not affect the vasorelaxation to sodium nitroprusside in vitro and in some studies even has augmented the response (29-31). Therefore, endothelial dysfunction itself could not have caused the blunted forearm blood flow response to sodium nitroprusside in our hypercholesterolemic subjects. The abnormal vasodilator response to nitroprusside that occurred in our hypercholesterolemic subjects contrasts with the reports that endothelium-independent relaxation is preserved in vascular rings exposed to hypercholesterolemic conditions $(7,8)$. Other investigators, however, have reported reduced potency of nitrovasodilators in aortae from hypercholesterolemic rabbits and from atherosclerotic human coronary arteries $(4,32)$.

Vasodilation to sodium nitroprusside and EDRF are probably mediated by the same mechanism (33). These agents cause vasodilation by stimulating the activity of soluble guanylate cyclase within the vascular smooth muscle, thereby elevating tissue levels of cyclic $\operatorname{GMP}(21,22,29)$. Activation of soluble guanylate cyclase is triggered by formation of a nitrosyl-porphyrin complex during metabolism of the nitrovasodilator $(33,34)$. In addition to the heme moiety of guanylate cyclase, there are sulfhydryl groups associated with the enzyme that modulate its activity. Oxidation of the heme iron or the associated thiol groups inactivate the enzyme (34-37). Hypercholesterolemia may alter the redox state of the vascular smooth muscle (38), thereby reducing responsiveness of the vessel wall to endogenous and exogenous nitrovasodilators. Also, both EDRF and sodium nitroprusside may cause vasodilation by inducing hyperpolarization of vascular smooth muscle $(39,40)$. It is therefore conceivable that alterations in the lipid bilayer could affect ionic fluxes, depress hyperpolarization, and reduce the vasodilator response to methacholine chloride and sodium nitroprusside.

Another explanation for our findings would be that in the hypercholesterolemic subjects, vasodilation is offset by a heightened responsiveness of vascular smooth muscle to endogenous vasoconstrictors. In some animal models of atherosclerosis, there is an increased sensitivity to vasoconstrictor agents, which could effectively reduce the response to vasodilators (1-3). This may be due to a direct effect of cholesterol upon the vascular smooth muscle. In vitro, cholesterol induces small contractions of canine coronary arteries and sensitizes these vessels to extracellular calcium (9). In our study, increased responsiveness to endogenous vasoconstrictors is not a likely explanation for impaired vasodilation, because the vasoconstriction to the alpha-adrenergic agonist, phenylephrine, was not potentiated in the hypercholesterolemic subjects.

Structural changes in the resistance vessels. Ischemia is a potent vasodilator stimulus that overcomes vascular tone caused by vasoconstrictor stimuli. In the absence of flow-limiting lesions, the forearm blood flow response to reactive hyperemia is thought to reflect the maximal vasodilator capacity of the resistance vessels (41). Reduced maximal vasodilation is generally attributed to structural abnormalities within the vessel and has been reported in patients with hypertension or congestive heart failure. In addition, Zelis et al. (42) found that reactive hyperemic blood flow was reduced in the legs of patients with type III hyperlipidemia. Although this study does not prove the impaired vascular response is confined to nitrovasodilators, we have ruled out a generalized defect in vasodilator capacity due to structural abnormalities since reactive hyperemic blood flow was the same in both groups.

Limitations of this study. We cannot be certain that our hypercholesterolemic subjects did not have atherosclerosis. However, this possibility is unlikely because this process rarely affects the upper extremity in the absence of clinically apparent disease in other circulations (11). Our patients were young and did not manifest any symptoms or signs of occlusive arterial disease in any vascular bed. In the absence of flow limiting lesions of the conduit vessels, plethysmographic measurements of forearm blood flow reflect vasomotion at the level of resistance vessels. Unlike the larger vessels, resistance vessels do not develop atheromatous lesions. Therefore, the attenuated response to infused vasodilators in the hypercholesterolemic subjects, was probably not confounded by the presence of atherosclerosis.

Clinical significance. These data strongly suggest that abnormalities of vascular function occur in hypercholesterolemic individuals in the absence of atherosclerosis. They do not, however, prove that abnormal vascular function precedes the development of atherosclerosis. This possibility is intriguing because abnormalities of the endothelium or vascular smooth muscle caused by hypercholesterolemia may facilitate vascular injury caused by platelet-vascular wall interactions, circulating macrophages, mitogens, and other substances involved in the development of atherosclerosis (43).

Furthermore, one might speculate that early treatment of hypercholesterolemia will prevent atherosclerosis by preserving vascular function. In this regard, it is noteworthy that treatment reverses or prevents abnormal vasodilator responses in atherosclerotic vessels of animals initially fed a high cholesterol diet and of humans with type III hyperlipidemia (42, 44-46). Furthermore, endothelium-dependent vasorelaxation is not impaired in coronary arteries isolated from hypercholesterolemic swine fed a diet supplemented with fish oil (45). A low cholesterol diet reverses endothelial dysfunction in atherosclerotic cynomolgus monkeys and inhibitors of HMG Co-A reductase normalize endothelium-dependent relaxation in the thoracic aorta isolated from hypercholesterolemic rabbits $(44$, 46). It will be extremely important to determine if the impaired vasodilator response in hypercholesterolemic patients can also be reversed by treatment.

Conclusions. In this series of experiments the vasodilator responses to methacholine chloride and to sodium nitroprusside were blunted in patients with hypercholesterolemia. We hypothesize that the hypercholesterolemic state impairs delivery of nitrovasodilators to the vascular media, modulates intracellular metabolism of these substances, or otherwise reduces their effects by inactivating guanylate cyclase or depressing hyperpolarization of vascular smooth muscle.

\section{Acknowledgments}

The authors gratefully acknowledge Ms. Joanne Normandin for manuscript preparation.

Dr. Creager and Dr. Loscalzo are each recipients of National Heart, Lung and Blood Institute (NHLBI) Research Career Development Awards, HL01768 and HL02273, respectively. Dr. Mendelsohn has 
received a NHLBI Clinical Investigation Award, HL02154, and Dr. Dzau is a recipient of an American Heart Association Established Investigator Award. This work was supported, in part, by a grant from the National Institutes of Health (HL-040411) and a grant from E. R. Squibb and Sons.

\section{References}

1. Henry, P. D., and M. Yokoyama. 1980. Supersensitivity of atherosclerotic rabbit aorta to ergonovine. J. Clin. Invest. 66:306-313.

2. Rosendorff, C., J. I. E. Hoffman, E. D. Verrier, J. Rouleau, and L. E. Boerboom. 1981. Cholesterol potentiates the coronary artery response to norepinephrine in anesthetized and conscious dogs. Circ. Res. 48:320-329.

3. Heistad, D. D., M. L. Armstrong, M. L. Marcus, D. J. Piegors, and A. L. Mark. 1984. Augmented responses to vasoconstrictor stimuli in hypercholesterolemic and atherosclerotic monkeys. Circ. Res. 54:711-718.

4. Verbeuren, T. J., F. H. Hordaens, L. L. Zonnekeyn, G. E. Van Hove, M.-C. Coene, and A. G. Herman. 1986. Effect of hypercholesterolemia on vascular reactivity in the rabbit. Circ. Res. 58:552-564.

5. Shimokawa, H., H. Tomoike, S. Nabeyama, H. Yamamot, H. Araki, M. Nakamura, Y. Ishii, and K. Tanaka. 1983. Coronary artery spasm induced in atherosclerotic miniature swine. Science (Wash. DC). 221:560-562.

6. Freiman, P. C., G. G. Mitchell, D. D. Heistad, M. L. Armstrong and D. G. Harrison. 1986. Atherosclerosis impairs endothelium-dependent vascular relaxation to acetylcholine and thrombin in primates. Circ. Res. 58:783-789.

7. Andrews, H. E., K. R. Bruckdorfer, R. C. Dunn, and M. Jacobs. 1987. Low-density lipoproteins inhibit endothelium-dependent relaxation in rabbit aorta. Nature (Lond.). 327:237-239.

8. Cohen, R. A., K. M. Zitnay, C. C. Haudenschild, and L. D. Cunningham. 1988. Loss of selective endothelial cell vasoactive functions caused by hypercholesterolemia in pig coronary arteries. Circ. Res. 63:903-910.

9. Yokoyama, M., and P. D. Henry. 1979. Sensitization of isolated canine coronary arteries to calcium ions after exposure to cholesterol. Circ. Res. 45:479-486.

10. Hokanson, D. E., D. S. Sumner, and D. E. Strandness, Jr. 1975. An electrically calibrated plethysmograph for direct measurement of limb blood flow. IEEE (Inst. Electr. Electron. Eng.) Trans. Biomed. Eng. 22:25-29.

11. Juergens, J. L., and P. E. Bernatz. 1980. Atherosclerosis of the extremities. In Peripheral Vascular Diseases. J. L. Juergens, J. A. Spittell, and J. F. Fairbairn, II, editors. W. B. Saunders Company, Philadelphia, PA. 253-293.

12. Shimokawa, H., J. Y. T. Lam, J. H. Chesebro, E. J. W. Bowie, and P. M. Vanhoutte. 1987. Effects of dietary supplementation with cod-liver oil on endothelium-dependent responses in porcine coronary arteries. Circulation. 76:898-905.

13. Vanhoutte, P. M., E. P. Coen, W. J. De Ridder, and T. J. Verbeuren. 1979. Evoked release of endogenous norepinephrine in the canine saphenous vein. Circ. Res. 45:608-614.

14. Creager, M. A., C.-S. Liang, and J. D. Coffman. 1985. Beta adrenergic-mediated vasodilator response to insulin in the human forearm. J. Pharmacol. Exp. Ther. 235:709-714.

15. Winer, B. J. 1971. Statistical principles in experimental design. 2nd Ed. McGraw-Hill Book Co., Inc., New York. 907 pp.

16. Wilcoxon, F., and R. A. Wilcox. 1971. Some rapid approximate statistical procedures. Pearl River, New York.

17. Ludmer, P. L., A. P. Selwyn, T. L. Shook, R. R. Wayne, G. H. Mudge, R. W. Alexander, and P. Ganz. 1986. Paradoxical vasoconstriction induced by acetylcholine in atherosclerotic coronary arteries. N. Engl. J. Med. 315:1046-1051.

18. Furchgott, R. F., and J. V. Zawadski. 1980. The obligatory role of endothelial cells in the relaxation of arterial smooth muscle by acetylcholine. Nature (Lond.). 288:373-376.

19. De Mey, J. G., M. Claeys, and P. M. Vanhoutte. 1982. Endothelium-dependent inhibitory effects of acetylcholine, adenosine triphosphate, thrombin and arachidonic acid in the canine femoral artery. J. Pharmacol. Exp. Ther. 222:166-173.

20. Luscher, T. F., J. P. Cooke, B. S. Houston, R. J. Neves, and P. M. Vanhoutte. 1987. Endothelium-dependent relaxations in human arteries. Mayo Clin. Proc. 62:601-660.

21. Ignarro, L. J., R. G. Harbison, K. S. Wood, and P. J. Kadowitz. 1986. Activation of purified soluble guanylate cyclase by endothelium-derived relaxing factor from intrapulmonary artery and vein: stimulation by acetylcholine, bradykinin and arachidonic acid. $J$. Pharmacol. Exp. Ther. 237:893-900.

22. Martin, W., G. M. Villani, D. Jothianandan, and R. F. Furchgott. 1985. Selective blockade of endothelium-dependent and glyceryl trinitrate-induced relaxation by hemoglobin and by methylene blue in the rabbit aorta. J. Pharmacol. Exp. Ther. 232:708-716.

23. Palmer, R. M. J., D. D. Rees, D. S. Ashton, and S. Moncada. 1988. L-arginine is the physiological precursor for the formation of nitric oxide in endothelium-dependent relaxation. Biochem. Biophys. Res. Commun. 153:1251-1256.

24. Bossaller, C., G. B. Habib, H. Yamamoto, C. Williams, S. Wells, and P. D. Henry. 1987. Impaired muscarinic endothelium-dependent relaxation and cyclic guanosine 5 '-monophosphate formation in atherosclerotic human coronary artery and rabbit aorta. J. Clin. Invest. 79:170-174.

25. Forstermann, U., A. Mugge, U. Alheid, A. Haverich, and J. C. Frolich. 1988. Selective attenuation of endothelium-mediated vasodilation in atherosclerotic human coronary arteries. Circ. Res. 62:185190.

26. Ross, R., and L. Harkes. 1976. Hyperlipidemia and atherosclerosis. Science (Wash. DC). 193:1094-1100.

27. Yamamoto, H., C. Bossaller, J. Cartwright, Jr., and P. D. Henry. 1988. Videomicroscopic demonstration of defective cholinergic arteriolar vasodilation on atherosclerotic rabbit. J. Clin. Invest. 81:1752-1758.

28. Osborne, J. A., M. J. Siegman, A. W. Sedar, S. U. Mooers, and A. M. Lefer. 1989. Lack of endothelium-dependent relaxation in coronary resistance arteries of cholesterol-fed rabbits. Am. J. Physiol. 256:C591-C597.

29. Ignarro, L. J., and P. J. Kadowitz. 1985. Pharmacological and physiological role of cyclic AMP in vascular smooth muscle relaxation. Annu. Rev. Pharmacol. 25:171-191.

30. Tesfamariam, B., and W. Halpern. 1988. Endothelium-dependent and endothelium-independent vasodilation in resistance arteries from hypertensive rats. Hypertension. 11:440-444.

31. Shirasaki, Y., C. Su, T. J.-F. Lee, P. Kolm, W. H. Cline, Jr., and G. A. Nickols. 1986. Endothelial modulation of vascular relaxation to nitrovasodilators in aging and hypertension. J. Pharmacol. Exp. Ther. 239:861-866.

32. Förstermann, U., A. Mügge, U. Alheid, A. Haverich, and J. C. Frölich. 1988. Selective attenuation of endothelium-mediated vasodilation in atherosclerotic human coronary arteries. Circ. Res. 62:185190.

33. Murad, F. 1986. Cyclic guanosine monophosphate as a mediator of vasodilation. J. Clin. Invest. 73:1-5.

34. Waldman, S. C., and F. Murad. 1988. Biochemical mechanisms underlying vascular smooth muscle relaxation: the guanylate cyclase-cyclic GMP system. J. Cardiovasc. Pharmacol. 12(Suppl. 15):S115-S118.

35. Craven, P. A., and F. R. DeRubertis. 1978. Effects of thiol inhibitors on hepatic guanylate cyclase activity: evidence for the involvement of vicinal dithiols in the expression of basal and agoniststimulated activity. Biochim. Biophys. Acta. 524:2231-2244.

36. Craven, P. A., and F. R. DeRubertis. 1978. Restoration of the responsiveness of purified guanylate cyclase to nitrosoguanidine, nitric 
oxide, and related activators by heme and hemeproteins. J. Biol. Chem. 253:8433-8443.

37. Brandwein, H. J., J. A. Lewicki, and F. Murad. 1981. Reversible inactivation of guanylate cyclase by mixed disulfide formation. $J$. Biol. Chem. 256:2958-2962.

38. Ylä-Herttuala, S., W. Palinski, M. E. Rosenfeld, S. Parthasarathy, T. E. Carew, S. Butlaer, J. L. Witztum, and D. Steinberg. 1989. Evidence for the presence of oxidatively modified LDL in human atherosclerotic lesions. Circulation. 80(Suppl. II):II-160.

39. Rapoport, R. M., and F. Murad. 1983. Effect of ouabain and alterations in potassium concentration on relaxation induced by sodium nitroprusside. Blood Vessels. 20:255-264.

40. Feletou, M., and P. M. Vanhoutte. 1988. Endothelium-dependent hyperpolarization of canine coronary smooth muscle. $\mathrm{Br}$. $J$. Pharmacol. 93:515-524.

41. Patterson, G. C., and R. F. Whelan. 1955. Reactive hyperaemia in the human forearm. Clin. Sci. 14:197-211.
42. Zelis, R., D. T. Mason, E. Braunwald, and R. I. Levy. 1970. Effects of hyperlipoproteinemias and their treatment on the peripheral circulation. J. Clin. Invest. 49:1007-1115.

43. Ross, R. 1986. The pathogenesis of atherosclerosis-an update. N. Engl. J. Med. 314:488-500.

44. Harrison, D. G., M. L. Armstrong, P. C. Freiman, and D. D. Heistad. 1987. Restoration of endothelium-dependent relaxation by dietary treatment of atherosclerosis. J. Clin. Invest. 80:1808-1811.

45. Shimokawa, H., and P. M. Vanhoutte. 1988. Dietary cod liver oil improves endothelium-dependent responses in hypercholesterolemic and atherosclerotic porcine coronary arteries. Circulation. 78:1421-1430.

46. Osborne, J. A., P. H. Lento, M. R. Siegfried, G. H. Stahl, B. Fusman, and A. M. Lefer. 1989. Cardiovascular effects of acute hypercholesterolemia in rabbits. Reversal with lovostatin treatment. J. Clin. Invest. 83:465-473. 